\title{
Biomass derived graphene-like activated and non-activated porous carbon for advanced supercapacitors
}

\author{
KASINATH OJHA ${ }^{\mathrm{a}}$, BHARAT KUMAR ${ }^{\mathrm{a}}$ and ASHOK K GANGULI ${ }^{\mathrm{a}, \mathrm{b}, * \mathbb{D}}$ \\ ${ }^{a}$ Department of Chemistry, Indian Institute of Technology Delhi, HauzKhas, New Delhi 110 016, India \\ ${ }^{b}$ Institute of Nano Science and Technology, Mohali, Phase - 10, Sector - 64, Punjab 160 062, India \\ Email: ashok@chemistry.iitd.ac.in
}

MS received 19 October 2016; revised 15 January 2017; accepted 31 January 2017

\begin{abstract}
Graphene-like activated and non-activated carbon nanostructures were synthesized from various natural sources like sugar, rice husk and jute. These carbon nanostructures were characterized using SEM, FTIR and Raman spectroscopy, surface area and thermogravimetric analysis. The electrochemical studies of these carbon materials confirm their promising characteristics for supercapacitor applications. Activated carbon nanostructures exhibit higher specific capacitance compared to that of non-activated carbons (non-Ac sugar). The activated carbon (Ac-jute) exhibits maximum specific capacitance of $476 \mathrm{~F} / \mathrm{g}$ at an applied current density of $0.2 \mathrm{~A} / \mathrm{g}$ which is much higher than that of graphene oxide $(\mathrm{GO})$.
\end{abstract}

Keywords. Graphene; biomass; supercapacitor; porous carbon; energy storage.

\section{Introduction}

Energy storage is the primary component of sustainable energy systems. Renewable energy sources like photovoltaics, wind turbines and hydroelectricity are not yet adopted as primary energy sources. Energy storage technologies have the potential to store these renewable energy and then provide the access to the energy on demand. Energy storage systems also play a very crucial role in energy transportation. Currently, the main energy storage systems are batteries where energy can be stored electrochemically and the chemical reactions can release the energy in terms of electrical carriers which can be extracted to the external circuit. However, batteries have low power density and are unable to retain its storage ability over time. Electrochemical capacitors, mainly supercapacitors or sometimes Ultracapacitors, are similar to batteries but store energy electrostatically rather than in chemical form, and do not involve any chemical reactions as in batteries. ${ }^{1,2}$ The supercapacitors store electrical charge on conducting materials having very high surface area. The main features of supercapacitors are, (a) high power density and can be charged very quickly, and (b) they do not lose their energy storage ability over time as no chemical degradation takes place. Unlike batteries, the low energy density of the supercapacitors is the main limitation.

*For correspondence
Supercapacitors are divided into two categories: electrochemical double layer capacitors (EDLC) and pseudocapacitors. In EDLCs, charge accumulation takes place at the interface between electrolyte and electrode and in pseudocapacitors, conducting materials e.g., metals, metal oxides and organic polymers are involved which follow Faradaic mechanism to accumulate charge. ${ }^{3}$ Mainly, carbon based materials with high specific surface area are involved in EDLCs. Carbon based supercapacitors have been investigated and used most widely because of their high surface area, ease of processability, electrochemical inertness, controllable porosity and low cost. ${ }^{4}$ Different carbon materials, like activated carbon sheets, carbon nanotubes, porous templated carbons, carbon fibers, graphene and graphene oxides, have been investigated extensively as EDLCs. ${ }^{5}$ The maximum specific capacitance of $550 \mathrm{~F} / \mathrm{g}$ can be obtained from graphene. Single layer graphene having specific surface area of $\sim 2630 \mathrm{~m}^{2} / \mathrm{g}$ exhibits the gravimetric capacitance of $355 \mathrm{~F} / \mathrm{g} .{ }^{6}$ Rouff et al., have demonstrated that $\mathrm{KOH}$ activation of microwave exfoliated GO exhibits a specific surface area of 3100 $\mathrm{m}^{2} / \mathrm{g}$ which is beyond the theoretical limit. ${ }^{7}$ A simple DVD LightScribe writer was used for Laser reduction of graphite oxide to graphene having specific surface area of $1520 \mathrm{~m}^{2} / \mathrm{g}$ and conductivity of $1738 \mathrm{~S} / \mathrm{m}^{8}$ Activated carbon with high surface area can be derived from organic precursors having high carbon content by carbonization followed by oxidation in $\mathrm{CO}_{2}$, water vapor and $\mathrm{KOH}$. Various porous carbon materials with 
varying pore size and pore structure can be synthesized using templates. For example, Zeolite has been used for synthesis of ordered microporous carbon materials and mesoporous silica nanoparticles (MCM-48, HMS, SBA-15, MCF, and MSU-X) were used for the synthesis of mesoporous carbons having ordered pore structure. ${ }^{9}$ Li et al., have discussed the properties of different types of carbons with their dimensionality and cost. ${ }^{10}$ The double layer capacitance of activated carbon is in the range of $100-120 \mathrm{~F} / \mathrm{g}$ in organic electrolyte and in the range of $150-300 \mathrm{~F} / \mathrm{g}$ in aqueous electrolyte. ${ }^{11}$ Graphene-like porous hollow carbon materials having high specific surface area and pores have been shown to exhibit high specific capacitance than that of solid microspheres. ${ }^{12}$ Multilayer carbon nanotubes ${ }^{13}$ have been shown to be a possibile supercapacitor material with specific capacitance of $\sim 135 \mathrm{~F} / \mathrm{g}$. Nitrogen doped carbon nanostructures have been shown to exhibit specific capacitance of $300 \mathrm{~F} / \mathrm{g}$ in acidic electrolyte. ${ }^{14}$ Beguin et al., have reported the specific capacitance of various activated carbon by varying specific surface area from $800 \mathrm{~m}^{2} / \mathrm{g}$ to $3000 \mathrm{~m}^{2} / \mathrm{g}$, a maximum specific capacitance of $357 \mathrm{~F} / \mathrm{g}$ was obtained. ${ }^{15}$

Biomass derived carbon materials have been investigated for supercapacitor applications. ${ }^{16-18}$ N-rich carbon derived from proteins exhibit supercapacitor properties with specific capacitance of $390 \mathrm{~F} / \mathrm{g} .{ }^{16}$ Microporous carbon nanoplates were synthesized from regenerated silk and it exhibited specific capacitance of $264 \mathrm{~F} / \mathrm{g}$ in aqueous electrolyte. ${ }^{19}$ 3D dendritic-like hierarchical porous carbon aerogels exhibit good specific capacitance of $368 \mathrm{~F} / \mathrm{g}$ at $0.05 \mathrm{~A} / \mathrm{g}$ in $\mathrm{KOH} .{ }^{20}$ Lotus seedpods-derived porous carbon shows outstanding capacitive behavior with $402 \mathrm{~F} / \mathrm{g}$ at $0.5 \mathrm{~A} / \mathrm{g}$ due to high surface area, optimum pore size and high oxygen containing functionalities. ${ }^{21}$ Activated porous carbon synthesized from biomass Paulownia flower shows specific capacitance of $297 \mathrm{~F} / \mathrm{g}$ at $1 \mathrm{~A} / \mathrm{g}$ current density in $\mathrm{H}_{2} \mathrm{SO}_{4}$ electrolyte. ${ }^{22}$ Gelatin was mixed with boric acid and annealed to get $\mathrm{B} / \mathrm{N}$ co doped carbon. ${ }^{23}$ which exhibits specific capacitance of $358 \mathrm{~F} / \mathrm{g}$ at current density of $0.1 \mathrm{~A} / \mathrm{g}$. Wan et al., have shown higher specific capacitance of $306 \mathrm{~F} / \mathrm{g}$ of corn husk derived carbon at $10 \mathrm{~A} / \mathrm{g}$ current density compared to other biomass derived carbons. ${ }^{24}$ Recently, rice husk-derived activated carbon having surface area of $2696 \mathrm{~m}^{2} / \mathrm{g}$ exhibited specific capacitance of $147 \mathrm{~F} / \mathrm{g}$ whereas another report on activated carbon (surface area $=2681 \mathrm{~m}^{2} / \mathrm{g}$ ) from rice husk using $\mathrm{NaOH}$ showed specific capacitance of 198.4 F/g. ${ }^{25,26}$ Carbon material synthesized from natural cellulose at $1000^{\circ} \mathrm{C}$ have been shown to exhibit supercapacitor properties with specific capacitance of 107 $\mathrm{F} / \mathrm{g} .{ }^{27}$
Here, we have synthesized graphene-like activated and non-activated carbon sheets from starch. Similarly, we have also synthesized activated carbon nanostructures from natural sources like jute and rice husk. The supercapacitor properties of these carbon materials have been investigated and the specific capacitance was compared with that of graphene oxide and reduced graphene oxide.

\section{Experimental}

\subsection{Materials and synthesis procedure}

Activated and non-activated carbon nanomaterials have been synthesized from different natural sources e.g., sugar, jute and rice husk.

Interconnected activated and non-activated carbon sheets have been synthesized from starch. Briefly, starch $(2 \mathrm{~g})$ was ground well with $\mathrm{KOH}(1 \mathrm{~g})$ and heated at $200^{\circ} \mathrm{C}$ for $1 \mathrm{~h}$ followed by heating at $750^{\circ} \mathrm{C}$ for $3 \mathrm{~h}$ in $\mathrm{N}_{2}$ atmosphere. Later, the product was washed with dil. $\mathrm{HCl}$ solution. To get nonactivated carbon sheets, $2 \mathrm{~g}$ of starch and $1 \mathrm{~g}$ of pluronic F127 were mixed together in $50 \mathrm{~mL}$ water and then dried to powder. The powder was ground well and heated at $200^{\circ} \mathrm{C}$ for $1 \mathrm{~h}$ followed by heating at $750^{\circ} \mathrm{C}$ for $3 \mathrm{~h}$ in $\mathrm{N}_{2}$ atmosphere.

Jute fibers $(3 \mathrm{~g})$ were added to a mixture of conc. $\mathrm{H}_{2} \mathrm{SO}_{4}$ $(40 \mathrm{~mL})$ and water $(10 \mathrm{~mL})$ resulting in a black slurry which was then diluted with $500 \mathrm{~mL}$ water. The product was filtered and washed with water several times. The dry powder was ground well with $\mathrm{KOH}(1 \mathrm{~g})$ and heated at $750^{\circ} \mathrm{C}$ for $3 \mathrm{~h}$ in $\mathrm{N}_{2}$ atmosphere. The resulted activated carbon from jute was washed with dil. $\mathrm{HCl}$ solution.

Rice husk was mixed with $10 \mathrm{~g}$ of $\mathrm{NaOH}$ in $300 \mathrm{~mL}$ water and stirred for overnight. The material was filtered and dried. Dried husk $(4 \mathrm{~g})$ was mixed with $1 \mathrm{~g}$ of $\mathrm{KOH}$ and heated at $200^{\circ} \mathrm{C}$ for $1 \mathrm{~h}$ followed by heating at $750^{\circ} \mathrm{C}$ for $3 \mathrm{~h}$ in $\mathrm{N}_{2}$ atmosphere. The product was washed with dil. $\mathrm{HCl}$ solution followed by $\mathrm{HF}$ to etch out $\mathrm{SiO}_{2}$ from the product.

Graphene oxide and reduced graphene oxide have been synthesized from graphite oxide as reported earlier. ${ }^{28}$ Briefly, graphite has been oxidized to get graphite oxide and then it was exfoliated using sonication to get graphene oxide. Again, the graphite oxide was reduced and exfoliated at high temperature to get reduced graphene oxide.

\subsection{Characterization techniques}

A field-emission scanning electron microscope (FESEM, FEI 3G Quanta) operated at $20 \mathrm{kV}$ was used for the surface morphology analysis. FTIR spectrum was recorded in a Cary 660 FTIR spectrometer (Agilent). The samples were mixed with $\mathrm{KBr}$ and pelletized for the measurements. Raman spectra were recorded in a Confocal Raman spectrometer (model: Xplora, Horiba JobinYvon) using a Laser excitation at 785 $\mathrm{nm}$. Thermogravimetric analysis (TGA) were carried out in the temperature range of $50-900^{\circ} \mathrm{C}$ on PerkinElmer Pyris 
Diamond TGA/DTA system in $\mathrm{N}_{2}$ atmosphere at a heating rate of $10^{\circ} \mathrm{C} / \mathrm{min}$. Surface area of the samples were calculated from the $\mathrm{N}_{2}$ gas adsorption profile measured in a Quantachrome 2000e instrument.

\subsection{Electrochemical measurements}

Electrochemical measurements have been carried out using a three electrode system in Autolab (PGSTAT302N) electrochemical setup in $0.5 \mathrm{M} \mathrm{H}_{2} \mathrm{SO}_{4}$ electrolyte. $\mathrm{Ag} / \mathrm{AgCl}$ (sat. $\mathrm{KCl}$ ) and $\mathrm{Pt}$ wire were used as reference and counter electrodes, respectively. The working electrode was prepared on glassy carbon electrode $\left(0.03 \mathrm{~cm}^{2}\right) .5 \mathrm{mg}$ of catalyst was dispersed in a mixture of isopropanol $(300 \mu \mathrm{L})$, water $(180 \mu \mathrm{L})$ and Nafion $(20 \mu \mathrm{L})$. A drop of the mixture $(5 \mu \mathrm{L})$ was placed on a glassy carbon electrode $\left(\sim 0.03 \mathrm{~cm}^{2}\right)$ and air-dried for $10 \mathrm{~min}$. Mass loading of the catalyst on the electrode was $1.6 \mathrm{mg}-\mathrm{cm}^{-2}$. Cyclic voltammetry at different scan rates and galvanostatic charge-discharge at different current densities were carried out.

\section{Results and Discussion}

Carbon nanostructures were synthesized from starch by carbonization at $200^{\circ} \mathrm{C}$ followed by heating at $750^{\circ} \mathrm{C}$ in $\mathrm{N}_{2}$ atmosphere. Here, the non-activated carbon refers to carbon synthesized in the absence of any chemical activation. The oxygen containing functional groups in biomass will be removed during carbonization process. Overall, the non-activated carbon will have less functionalities and random defects leading to low conductivity. $\mathrm{KOH}$ was mixed with starch before carbonization to get activated carbon nanostructures. Chemical activation of carbon materials leads to generation of porous nanostructures with high specific surface area, defined distributions of microstructures and pore size. There are several chemicals like $\mathrm{KOH}, \mathrm{H}_{3} \mathrm{PO}_{4}, \mathrm{ZnCl}_{2}$, etc., which are used for chemical activation of carbon materials. These activation processes proceed via solid-solid reactions followed by solid-liquid reactions and they produce metallic potassium in the mixture which oxidizes carbon into carbon oxides and carbonates. There are other mechanisms like $\mathrm{KOH}$ transforming into $\mathrm{K}_{2} \mathrm{O}$ at $400^{\circ} \mathrm{C}$ which then reacts with $\mathrm{CO}_{2}$ to produce $\mathrm{K}_{2} \mathrm{CO}_{3}$. This chemical activation leads to porous carbon materials. $\mathrm{KOH}$ activation of carbon based materials have been reviewed earlier in detail. ${ }^{29}$ Similarly, jute fibers and rice husk were treated with $\mathrm{H}_{2} \mathrm{SO}_{4}$ and $\mathrm{NaOH}$, respectively, followed by carbonization in presence of $\mathrm{KOH}$ (Figure 1).

All these different carbon nanostructures were characterized after washing with dil. $\mathrm{HCl}$ solution. Rice husk contains silicates and during carbonization $\mathrm{SiO}_{2}$ formation takes place. The carbon product from rice husk was finally treated with $\mathrm{HF}$ to remove $\mathrm{SiO}_{2}$ impurity. The electrochemical properties of these carbon nanostructures were compared with that of graphene oxide and reduced graphene oxides which were synthesized from graphite. ${ }^{28}$ The SEM images show sheetlike morphology of the carbon materials (Figure 2). Figures $2 \mathrm{a}$ and $2 \mathrm{~b}$ show the sheet-like morphology of graphene oxide (GO) and reduced graphene oxide (rGO) obtained from thermal exfoliation/reduction of graphite oxide. The SEM image of the non-activated carbon from starch shows sheet morphology similar to rGO (Figure 2c). In case of chemical activation of the carbon nanostructures during synthesis, highly porous interconnected carbon sheets were observed.

Activated carbon from starch exhibits highly interconnected sheet-like morphology (Figure 2d). Similarly, carbon from jute also shows interconnected sheets (Figure 2e) whereas carbon from rice husk exhibits porous carbon matrix (Figure 2f). FTIR spectra show graphitic skeletal vibrational bands (Figure S1a-b in Supplementary Information). FTIR spectra suggests that GO having huge functionalities, get reduced to rGO with negligible functionalities. Non-activated carbon from sugar shows FTIR spectrum similar to that of rGO indicating lower functionalities (Figure S1a). Activated carbon nanostructures also exhibit lower functionalities similar to rGO (Figure S1b). Raman spectra show that these are defected carbon as D band is very

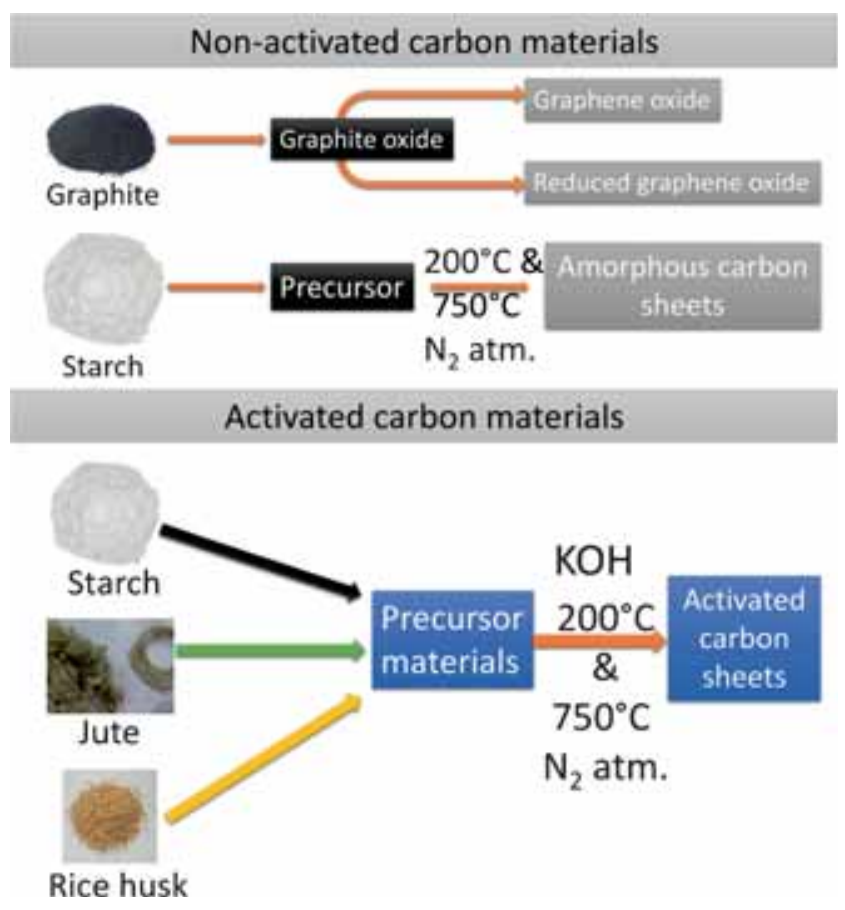

Figure 1. Schematic of the reaction steps for the synthesis of biomass derived carbon. 

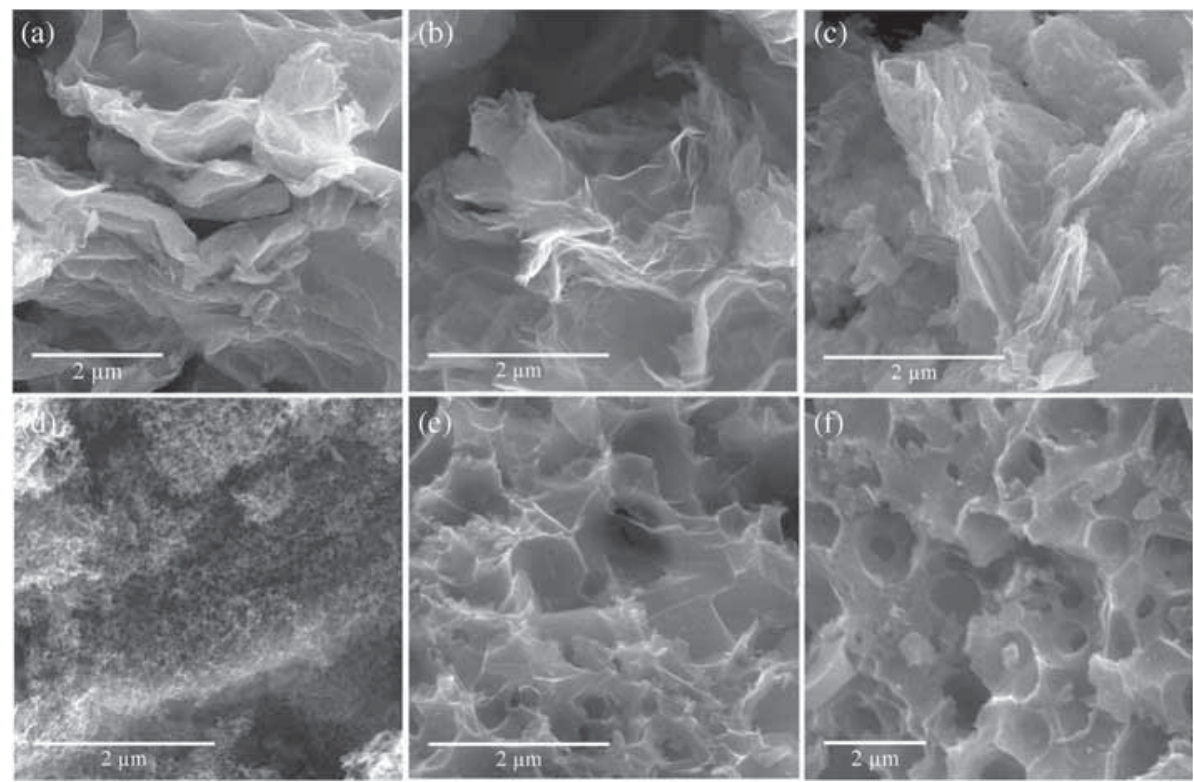

Figure 2. FESEM images of (a) GO, (b) rGO, (c) non-Ac-sugar, (d) Ac-sugar, (e) Ac-hemp and (f) Ac-rice husk.

high in intensity (Figure S1c-d in Supplementary Information). These are mostly amorphous, porous and multilayer carbon sheets. The thermogravimetric analysis (TGA) suggests that GO shows maximum weight loss due to its huge functionalities whereas rGO exhibits minimum weight loss and other carbon nanostructures exhibit similar weight loss (Figure S2). These nonactivated carbon flakes synthesized from starch have high BET surface area of $787 \mathrm{~m}^{2} / \mathrm{g}$ with large interlayer space, as observed type-IV hysteresis in $\mathrm{N}_{2}$ gas adsorption (Figure 3). This is due to fine flake-like morphology having porous structure. When we synthesized activated carbon from sugar in the presence of $\mathrm{KOH}$, uniform interconnected carbon sheet was observed. These are activated carbon material showing similar surface area $\left(655 \mathrm{~m}^{2} / \mathrm{g}\right)$. However, the activated carbon
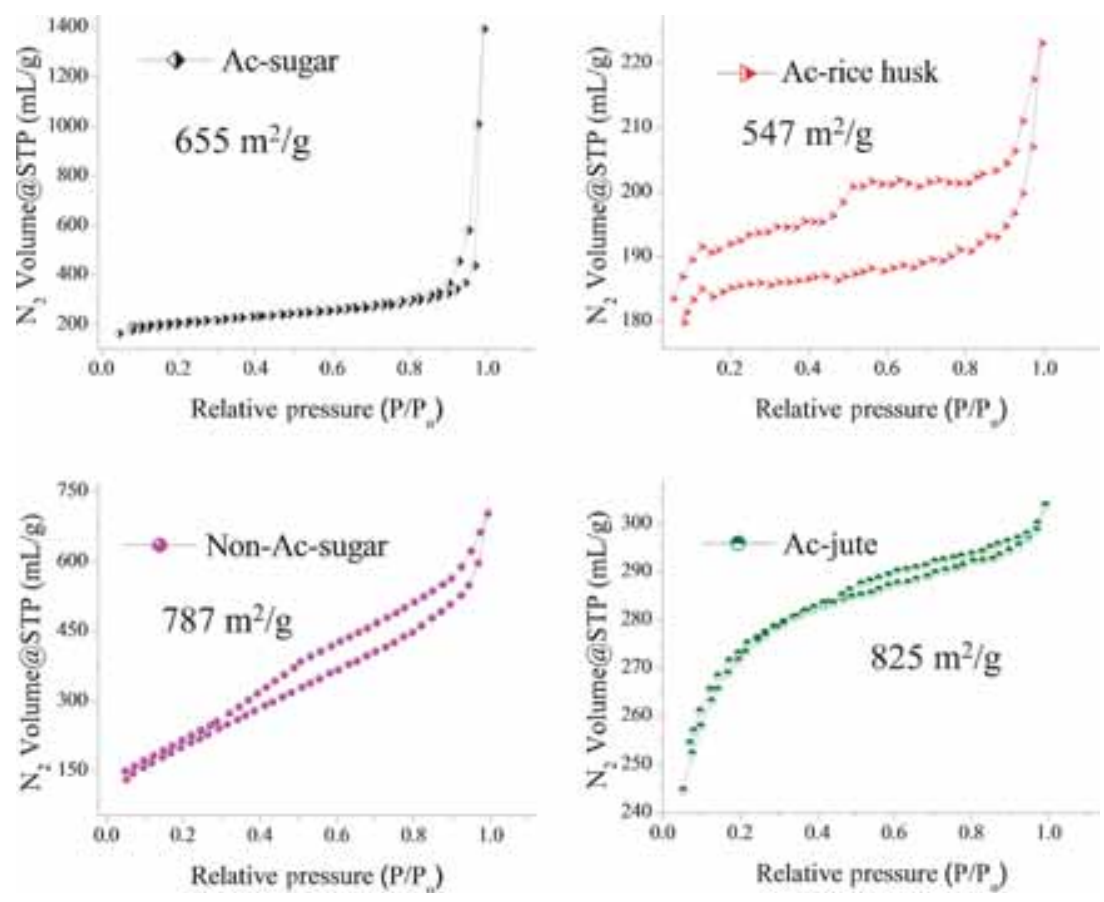

Figure 3. $\mathrm{N}_{2}$ gas adsorption profile of different carbon materials at different relative pressure $\left(\mathrm{P} / \mathrm{P}_{\mathrm{o}}\right)$ showing $\mathrm{BET}$ surface area. 
from jute exhibits maximum BET surface area of $825 \mathrm{~m}^{2} / \mathrm{g}$ whereas carbon from rice husk shows surface area of $547 \mathrm{~m}^{2} / \mathrm{g}$ (Figure 3).

The key components of crude biomass are cellulose, hemicellulose and lignin. ${ }^{30}$ Lignin decomposes at higher temperature $\left(>900^{\circ} \mathrm{C}\right)$ whereas cellulose and hemicellulose decompose at lower temperature $(\sim 400$ $\left.500^{\circ} \mathrm{C}\right){ }^{30}$ Therefore, during carbonization at $750^{\circ} \mathrm{C}$, the decomposition of cellulose and hemicellulose results in pores in the carbon materials as observed in SEM images. However, lignin, having aromatic units, creates interconnection between the aromatic rings which enhances the electrical conductivity of the materials. Rice husk contains $\sim 28 \%$ cellulose, $28 \%$ hemicellulose and $\sim 26 \%$ lignin. ${ }^{31}$ whereas jute fibers contains $\sim 65 \%$ cellulose, $\sim 17 \%$ hemicellulose and $\sim 16 \%$ lignin. ${ }^{32,33}$ Therefore, the total amount of cellulose and hemicellulose is higher in jute fibers which is responsible for its high surface area $\left(\sim 825 \mathrm{~m}^{2} / \mathrm{g}\right)$ and pores.

\subsection{Electrochemical studies}

Electrochemical investigations were carried out using a three electrode setup in $0.5 \mathrm{M} \mathrm{H}_{2} \mathrm{SO}_{4}$ (electrolyte) where these carbon nanostructures were deposited on GCE $\left(0.03 \mathrm{~cm}^{2}\right)$ and $\mathrm{Pt}, \mathrm{Ag} / \mathrm{AgCl}$ (sat. $\mathrm{KCl}$ ) were used as counter and reference electrodes, respectively. Mass loading of the samples were $1.6 \mathrm{mg} / \mathrm{cm}^{2}$. In
Figure 4, it is observed that the cyclic voltammograms of these carbon nanostructures exhibit large area under the curve indicating high total charge accumulations and their potential for electrochemical double layer capacitors (EDLCs). The activated carbon from sugar, rice husk and jute shows much higher area under the curve compared to that of non-activated carbon from sugar. Therefore, activated carbon materials show higher charge compared to non-activated carbon due to their higher amount of oxygen-containing functionalities in activated carbon materials as observed in the TGA studies (Figure S2 in Supplementary Information). The area under the cyclic voltammogram at a particular scan rate i.e., $100 \mathrm{mV} / \mathrm{s}$ increases in the order of non-ac-sugar <ac-sugar $<$ ac-rice husk $<$ acjute, which suggests that the specific capacitance also increases in the same order. This suggests that activated carbon nanostructures from jute have small resistance and short diffusional pathways for ion transportation. However, the cyclic voltammogram of activated carbon from rice-husk and jute exhibit reversible redox peaks corresponding to Quinone-hydroquinone species. ${ }^{34,35}$ This suggests that AC-jute and AC-rice husk contained quinone type functionalities which contribute as pseudo-capacitance to the overall specific capacitance of the materials.

Galvanostatic charge-discharge cycles of the samples at different applied current density show that
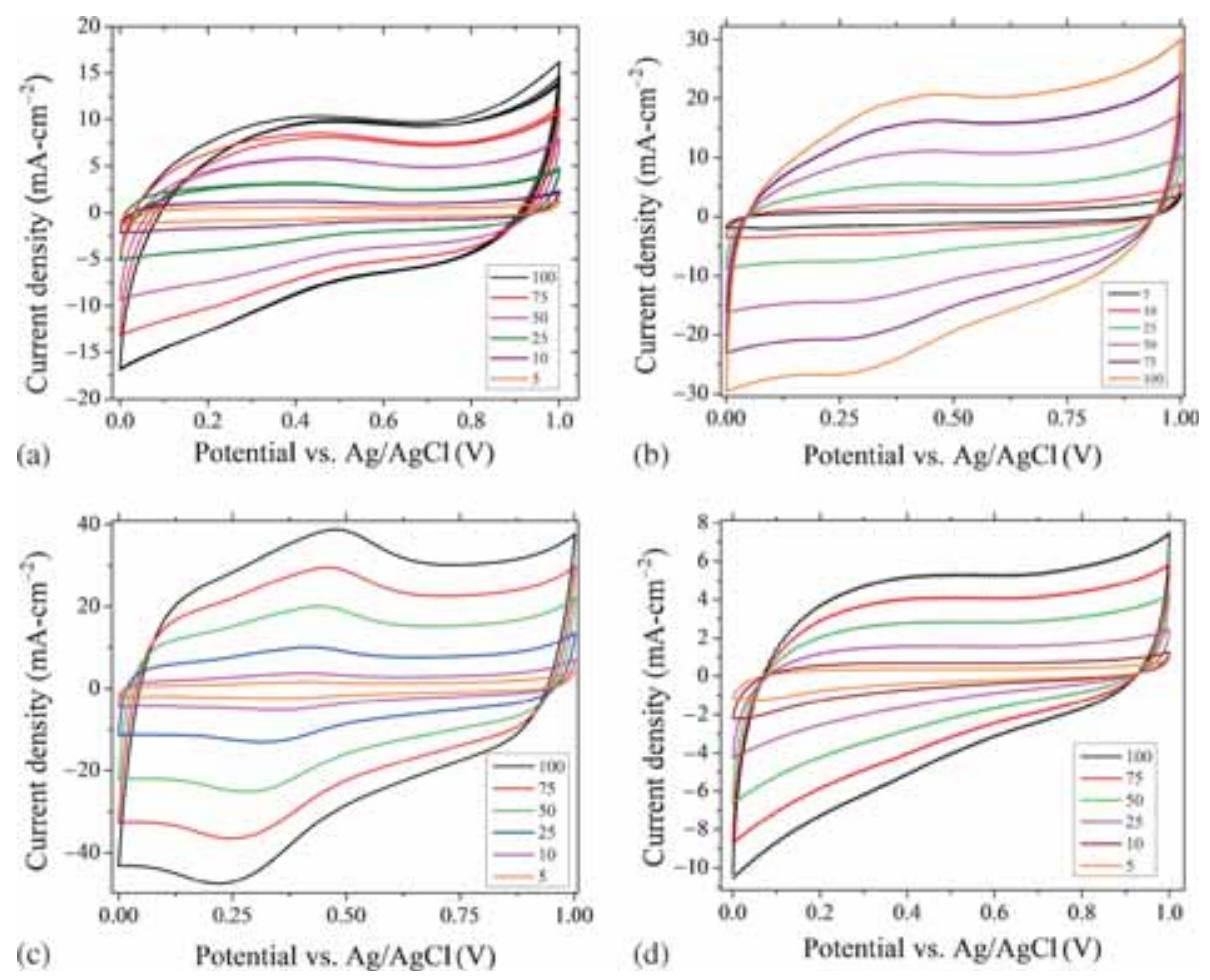

Figure 4. Cyclic voltammogram of (a) Ac-sugar, (b) Ac-rice husk, (c) Ac-jute and (d) non-Ac-sugar at various scan rate (figure legends are scan rate in $\mathrm{mV} / \mathrm{s}$ ). 

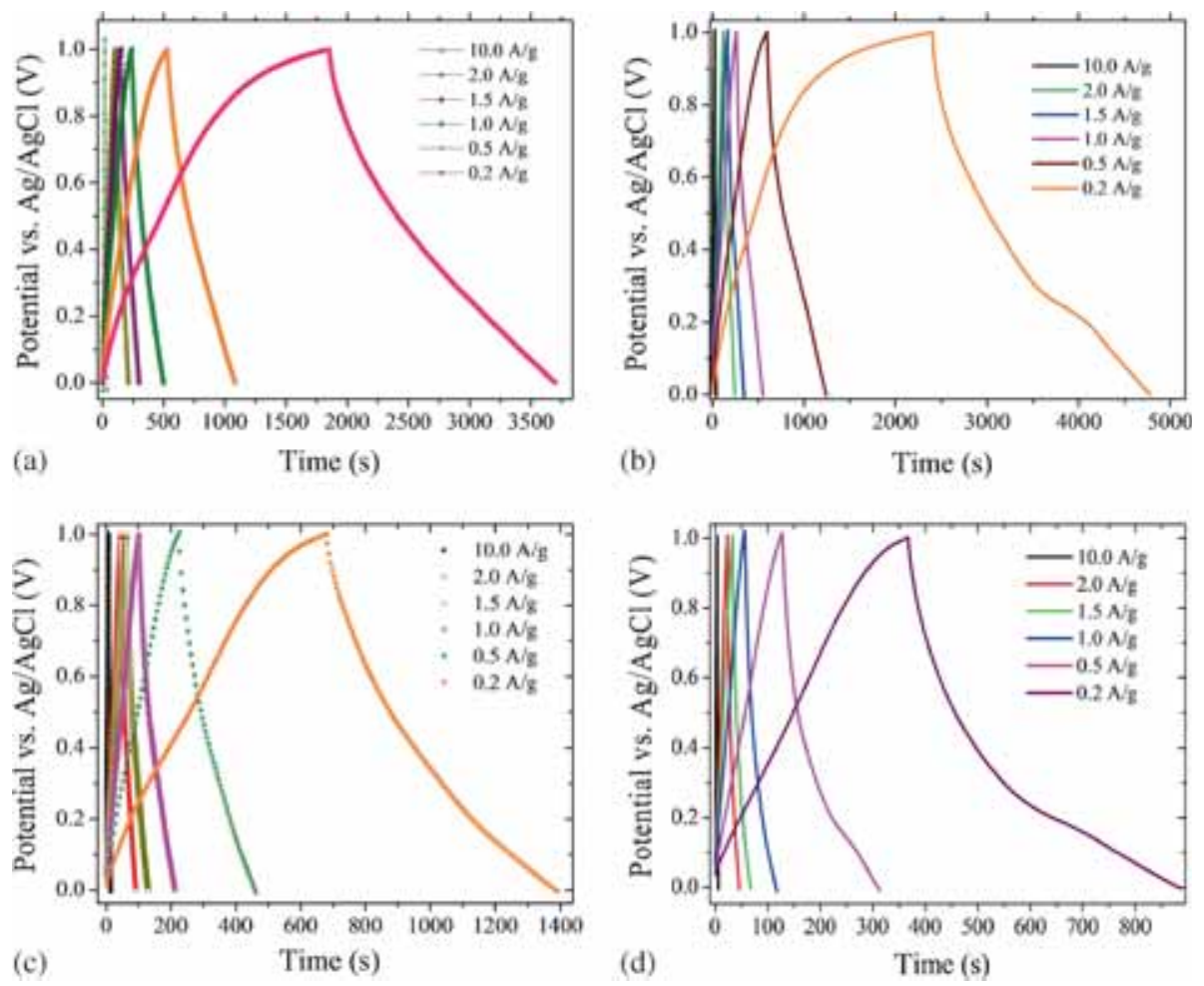

Figure 5. Galvanostatic charge-discharge cycles at different current density. (a) Ac-rice husk, (b) Ac-jute, (c) Ac-sugar and (d) non-Ac-sugar at various scan rates (figure legends are applied current density in $\mathrm{A} / \mathrm{g}$ ).

the charging or the discharging time decreases as we increase the current density (Figure 5). The discharging time at a particular applied current density i.e., 0.2 $\mathrm{A} / \mathrm{g}$ was observed maximum in case of activated carbon from jute (Figure 5b). The specific capacitance was calculated from the equation given below.

$$
C=\frac{I \Delta t}{m \Delta V}
$$

where, $\mathrm{C}$ is the specific capacitance $(\mathrm{F} / \mathrm{g}), \mathrm{I}$ is the current (A), $\Delta \mathrm{t}$ is the discharge time (s), $\Delta \mathrm{V}$ is the potential window $(\mathrm{V})$ and $\mathrm{m}$ is mass $(\mathrm{g})$ of the material loaded on the electrode. The calculated specific capacitance at current density of $0.2 \mathrm{~A} / \mathrm{g}$ and BET surface area are tabulated for various carbons nanostructures (Table S1 in Supplementary Information). The specific capacitance decreases with increasing applied current density (Figure 6a). Activated carbon from jute (Ac-jute) exhibits maximum specific capacitance of $476 \mathrm{~F} / \mathrm{g}$ and $200 \mathrm{~F} / \mathrm{g}$ at an applied current density of $0.2 \mathrm{~A} / \mathrm{g}$ and $10 \mathrm{~A} / \mathrm{g}$, respectively.

Earlier, graphene-like interconnected carbon sheet with high surface area $\left(2287 \mathrm{~m}^{2} / \mathrm{g}\right)$ were synthesized from hemp bast fibres which have been shown to exhibit
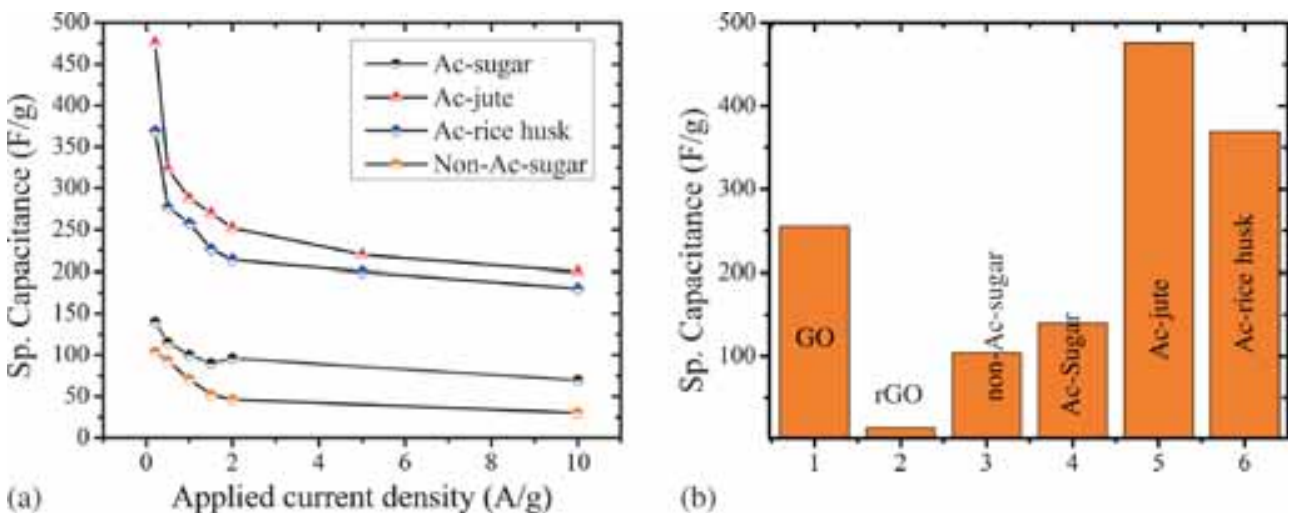

(b)

Figure 6. (a) Specific capacitance as a function of applied current density; (b) bar diagram of specific capacitance of various carbon materials at current density of $0.2 \mathrm{~A} / \mathrm{g}$. 


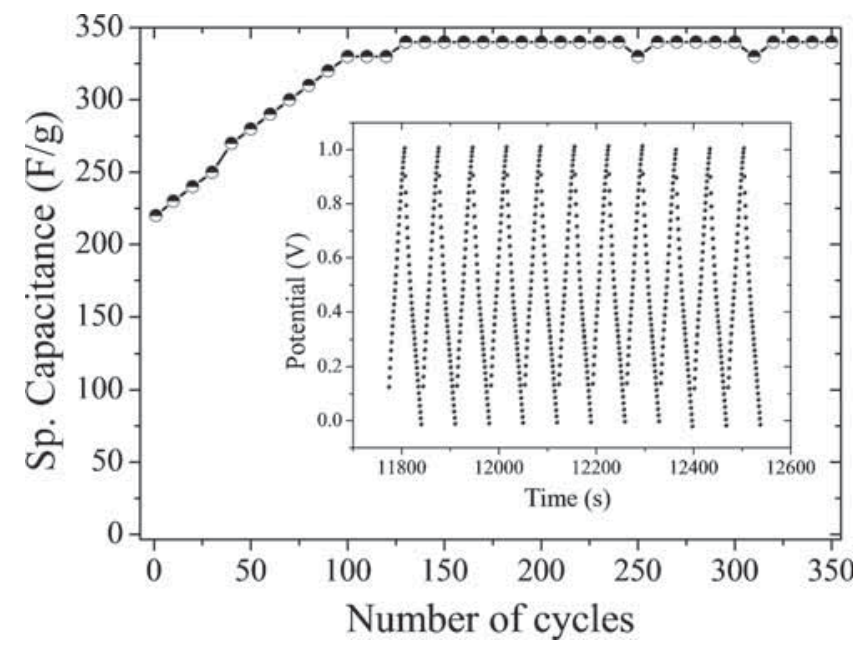

Figure 7. Variation of specific capacitance of Ac-jute during Charge-discharge cycles at an applied current density of $10 \mathrm{~A} / \mathrm{g}$ showing the stability upto 350 cycles. Inset shows the charge-discharge cycles in the potential range of $0-1 \mathrm{~V}$.

maximum specific capacitance of $144 \mathrm{~F} / \mathrm{g}$ in ionic liquid electrolyte. ${ }^{17}$ Activated carbon from rice husk exhibit specific capacitance of $369 \mathrm{~F} / \mathrm{g}$ and $258 \mathrm{~F} / \mathrm{g}$ at current density of $0.2 \mathrm{~A} / \mathrm{g}$ and $1 \mathrm{~A} / \mathrm{g}$, respectively, which is much higher than that of recent reports on activated carbon from rice husk..$^{25,26}$ The activated carbon nanostructures show higher specific capacitance than that of non-activated carbon (Figure 6a). Even these activated carbons (Ac-jute and Ac-rice husk) exhibit much higher specific capacitance compared to that of graphene oxide (Figure 6b). However, TGA analysis suggests that activated carbons have low functionalities than that of graphene oxide (Figure S2 in Supplementary Information). In spite of having higher amount of functionalities on GO surface, the specific capacitance is much lower than that of activated carbon. However, carbon nanostructures from starch exhibit lower specific capacitance i.e., $140 \mathrm{~F} / \mathrm{g}$ and $104 \mathrm{~F} / \mathrm{g}$ for activated and nonactivated, respectively (Figure 6a). In starch, absence of aromatic groups due to lignin results in highly porous carbon nanostructures with low electrical conductivity which in turn decreases the specific capacitance. Therefore synergistic effect of lignin and cellulose in the biomass is the key factor for high specific capacitance.

We have observed the specific capacitance of $255 \mathrm{~F} / \mathrm{g}$ and $14 \mathrm{~F} / \mathrm{g}$ for $\mathrm{GO}$ and $\mathrm{rGO}$, respectively, at an applied current density of $0.2 \mathrm{~A} / \mathrm{g}$. We have compared the specific capacitance of all these carbon nanostructures at an applied current density of $0.2 \mathrm{~A} / \mathrm{g}$ (Figure 6b) which suggests that $\mathrm{rGO}$ exhibits lowest specific capacitance of $14 \mathrm{~F} / \mathrm{g}$ due to lowest functionalities on rGO surface, as observed in TGA studies (Figure S2 in Supplementary Information).
We have carried out charge-discharge cycles for one of the materials i.e., Ac-jute upto 350 cycles at an applied current density of $10 \mathrm{~A} / \mathrm{g}$ to look at the stability of the material (Figure 7). Initially, upto 100 cycles, the specific capacitance increased from $220 \mathrm{~F} / \mathrm{g}$ to $340 \mathrm{~F} / \mathrm{g}$ and then it became constant at $340 \mathrm{~F} / \mathrm{g}$ which is quite high for supercapacitor applications. This suggests that the graphene-like activated carbon nanostructures derived from biomass can be a promising candidate for supercapacitors.

\section{Conclusions}

Various carbon nanostructures (activated and nonactivated) having sheet morphology have been synthesized from biomass. Amorphous carbon sheets were synthesized from starch and highly interconnected carbon sheets were observed when the reaction was carried out in presence of $\mathrm{KOH}$. Detailed electrochemical analysis suggests that activated carbon nanostructures exhibit higher specific capacitance compared to nonactivated carbons. Activated carbon (Ac-jute) shows higher specific capacitance of $476 \mathrm{~F} / \mathrm{g}$ at $0.2 \mathrm{~A} / \mathrm{g}$ which is much higher than that of graphene oxide $(255 \mathrm{~F} / \mathrm{g})$ and reduced graphene oxide (14 F/g). Quinone type functionalities in Ac-jute and Ac-rice husk contribute pseudo-capacitance to the overall specific capacitance. It has been observed that instead of higher amount of functionalities in graphene oxide compared to activated carbon nanostructures, activated carbon shows much higher specific capacitance than graphene oxide.

\section{Supplementary Information (SI)}

FTIR, Raman spectrum and TGA data are provided in the supplementary information which is available at www.ias.ac. in/chemsci.

\section{Acknowledgements}

AKG wants to thank DST and DeitY, Govt. of India for financial support. KO thanks UGC, Govt. of India for fellowship.

\section{References}

1. Winter M and Brodd R J 2004 What are batteries, fuel cells, and supercapacitors? What are batteries, fuel cells, and supercapacitors? Chem. Rev. 1044245

2. Burke A 2000 Ultracapacitors: Why, how, and where is the technology J. Power Sources 9137

3. Chee W K, Lim H N, Zainal Z, Huang N M, Harrison I and Andou Y 2016 Flexible graphene-based supercapacitors: A review J. Phys. Chem. C $\mathbf{1 2 0} 4153$ 
4. Pandolfo A G and Hollenkamp A F 2006 Carbon properties and their role in supercapacitors J. Power Sources 15711

5. Zhang L L, Zhou R and Zhao X S 2009 Carbon-based materials as supercapacitor electrodes Chem. Soc. Rev. 382520

6. Ji H, Zhao X, Qiao Z, Jung J, Zhu Y, Lu Y, Zhang L L, MacDonald A H and Ruoff R S 2014 Capacitance of carbon-based electrical double-layer capacitors Nat. Commun. 53317

7. Zhu Y, Murali S, Stoller M D, Ganesh K J, Cai W, Ferreira P J, Pirkle A, Wallace R M, Cychosz K A, Thommes M, Su D, Stach E A and Ruoff R S 2011 Carbon-based supercapacitors produced by activation of graphene Science 3321537

8. El-Kady M F, Strong V, Dubin S and Kaner R B 2012 Laser scribing of high-performance and flexible graphene-based electrochemical capacitors Science $\mathbf{3 3 5}$ 1326

9. Lee J, Kim J and Hyeon T 2006 Recent progress in the synthesis of porous carbon materials Adv. Mater. 182073

10. Jiang H, Lee P S and Li C 2013 Three-dimensional carbon based nanostructures for advanced supercapacitors Energy Environ. Sci. 641

11. Simon P and Gogotsi Y 2008 Materials for electrochemical capacitors Nat. Mater. 7845

12. Lv B, Zheng C, Xu L, Zhou X, Cao H and Liu Z 2015 Porous graphene-like materials prepared from hollow carbonaceous microspheres for supercapacitors ChemNanoMat 1422

13. Frackowiak E, Metenier K, Bertagna V and Beguin F 2000 Supercapacitor electrodes from multiwalled carbon nanotubes Appl. Phys. Lett. 772421

14. Zhao L, Fan L Z, Zhou M Q, Guan H, Qiao S, Antonietti M and Titirici M M 2010 Nitrogencontaining hydrothermal carbons with superior performance in supercapacitors Adv. Mater. 225202

15. Raymundo-Pinero E, Kierzek K, Machnikowski J and Beguin F 2006 Relationship between the nanoporous texture of activated carbons and their capacitance properties in different electrolytes Carbon $\mathbf{4 4} 2498$

16. Li Z, Xu Z, Tan X, Wang H, Holt C M B, Stephenson T, Olsen C and Mitlin D 2013 Mesoporous nitrogenrich carbons derived from protein for ultra-high capacity battery anodes and supercapacitors Energy Environ. Sci. 6871

17. Wang H, Xu Z, Kohandehghan A, Li Z, Cui K, Tan X, Stephenson T J, King'ondu C K, Holt C M B, Olsen B C, Tak J K, Harfield D, Anyia A O and Mitlin D 2013 Interconnected carbon nanosheets derived from hemp for ultrafast supercapacitors with high energy ACS Nano 75131

18. Dutta S, Bhaumik A and Wu K C 2014 Hierarchically porous carbon derived from polymers and biomass: Effect of interconnected pores on energy applications Energy Environ. Sci. 73574

19. Yun Y S, Cho S Y, Shim J, Kim B H, Chang S-J, Baek S J, Huh Y S, Tak Y, Park Y W, Park S and Jin H-J 2013 Microporous carbon nanoplates from regenerated silk proteins for supercapacitors Adv. Mater. 251993

20. Ma Y, Guo Y, Zhou C and Wang C 2016 Biomassderived dendritic-like porous carbon aerogels for supercapacitors Electrochim. Acta 210897
21. Liu B, Zhou X, Chen H, Liu Y and Li H 2016 Promising porous carbons derived from lotus seedpods with outstanding supercapacitance performance Electrochim. Acta 20855

22. Chang J, Gao Z, Wang X, Wu D, Xu F, Wang X, Guo $\mathrm{Y}$ and Jiang K 2015 Activated porous carbon prepared from paulownia flower for high performance supercapacitor electrodes Electrochim. Acta 157290

23. Ling Z, Wang Z, Zhang M, Yu C, Wang G and Dong Y 2016 Sustainable synthesis and assembly of biomassderived $\mathrm{B} / \mathrm{N}$ co-doped carbon nanosheets with ultrahigh aspect ratio for high-performance supercapacitors $A d v$. Funct. Mater. 26111

24. Song S, Ma F, Wu G, Ma D, Geng W and Wan J 2015 Facile self-templating large scale preparation of biomass-derived 3D hierarchical porous carbon for advanced supercapacitors J. Mater. Chem. A 318154

25. Le Van K and Luong Thi T T 2014 Activated carbon derived from rice husk by $\mathrm{NaOH}$ activation and its application in supercapacitor Prog. Nat. Sci. Mater. Int. 24 191

26. Teo E Y L, Muniandy L, Ng E-P, Adam F, Mohamed A R, Jose R and Chong K F 2016 High surface area activated carbon from rice husk as a high performance supercapacitor electrode Electrochim. Acta 192110

27. Jiang L, Nelson G W, Han S O, Kim H, Sim I N and Foord J S 2016 Natural cellulose materials for supercapacitors Electrochim. Acta 192251

28. Ojha K, Saha S, Kolev H, Kumar B and Ganguli A K 2016 Composites of graphene-Mo2C rods: Highly active and stable electrocatalyst for hydrogen evolution reaction Electrochim. Acta 193268

29. Wang J and Kaskel S $2012 \mathrm{KOH}$ activation of carbonbased materials for energy storage J. Mater. Chem. 22 23710

30. Deng J, Xiong $\mathrm{T}$, Wang $\mathrm{H}$, Zheng $\mathrm{A}$ and Wang $\mathrm{Y}$ 2016 Effects of cellulose, hemicellulose, and lignin on the structure and morphology of porous carbons ACS Sustain. Chem. Eng. 43750

31. Wannapeera J, Worasuwannarak $\mathrm{N}$ and Pipatmanomai S 2007 Product yields and characteristics of rice husk, rice straw and corncob during fast pyrolysis in a droptube/ fixed-bed reactor Songklanakarin J. Sci. Technol. 30393

32. Wang W, Cai Z and Yu J 2008 Study on the chemical modification process of jute fiber J. Eng. Fibers Fabr. 31

33. Del Rio J C, Rencoret J, Marques G, Li J, Gellerstedt G, Jesus J-B, Martinez A T and Gutierrez A 2009 Structural characterization of the lignin from jute (corchorus capsuiaris) fibers J. Agric. Food Chem. 5710271

34. Pham V H, Gebre T and Dickerson J H 2015 Facile electrodeposition of reduced graphene oxide hydrogels for high-performance supercapacitors Nanoscale 75947

35. Varley T S, Hirani M, Harrison G, Holt K B, Holt K B, Ziegler C, Caruana D J, Zang J, Millán-Barrios E J, Hu J, Foord J S, Holt K B, Hongthani W, Fermin D J, Zang J B, Wang Y H, Bian L Y, Zhang J H, Meng F W and et al. 2014 Nanodiamond surface redox chemistry: Influence of physicochemical properties on catalytic processes Faraday Discuss. 172349 